\title{
O ADVOGADO E A JUSTIÇA DO TRABALHO EM HOMENAGEM A UM SENHOR ADVOGADO
}

\author{
Júlio Assumpção Malhadas
}

Frof. Titular de Direito do Trabalho do Deto de Direito Privado da Fac. de Direito do Setor de Cîencias Jurídicas da UFPR. Membro do Instituto dos Advogados do Paraná. Acadêmico da Academia Nacional de Direito do Trabalho.

O Professor José Lamartine Corrêa de Oliveira Lyra, foi, sem sombra de dúvida, um Senhor Advogado. O advogado sempre alerta, sempre à disposição los que precisassem de uma providência jurídica, sempre disposto a lutar pelo direito alheio, mesmo pondo em risco até mesmo sua liberdade.

O advogado que não se contentava em ser advogado, mas fazia questão de fazer advogados dos jovens que lhe freqüentavam as aulas, a eles dispensando todas as atenções, onde quer que estivesse, razão de estar sempre cercado por eles e ser por eles amado.

O advogado que defendia as prerrogativas da classe e pugnava por aperfeiçoá-la e elevar-lhe o nível cultural.

Não sem razão, foi Presidente do Instituto dos Advogados do Paraná, Conselheiro da Seção do Paraná da Ordem dos Advogados do Brasil, e representante eleito da Seção no Conselho Federal da Ordem.

Sendo-nos dada oportunidade de participar desta homenagem coletiva a nosso pranteado colega, pareceu-nos que bem estaria aqui defender a prerrogativa da classe perante a Justiça do Trabalho, de onde se procura alijá-la, onde tem sido mal recebida.

f nossa homenagem a esse Senhor Advogado que em vida se chamou José Lamartine Corrêa de Oliveira Lyra.

1. Em estudo apresentado no Simpósio sobre o Ensino do Direito e a Formação do Advogado, promovido pelas Faculdades de Direito da Universidade de São Paulo, Associação dos Advogados de São Paulo e Associazione di Studi Sociali Latino-Americani,

R. Fac. Direito

Curitiba

a. 25

n. 25

p. $125-137,1989$

125 
em agosto de 1972 em São Paulo, um dos participantes - cujo nome não consta do exemplar mimeografado que temos - nos traz referências valiosas, de que nos servimos, esperando vir a coniecer o Autor para lhe agradecer.

Lembra esse estudo as palavras do monólogo de Jó (Livro de Jó, 29 - 12 a 16), como se referindo aos precursores dos advogados (e acrescentamos o versículo 11):

"A orelha que me ouvia, chamava-me bemaventurado, e o olho que me via dava testemunho de mim.

Porque eu tinha livrado o pobre que gritava, e o órfão, que não tinha quem o socorresse.

A bênção do que estava a perecer vinha sobre mim, e consolei o coração da viúva.

Eu me revesti da justiça: e a eqüidade me serviu, como de vestido e de diadema.

Eu fui o oiho do cego e o pé do coxo.

Eu era o pai dos pobres: e as causas de que eu não tinha conhecimento, eu me instruía com toda a diligência.",

e a exortação de Isaías (nc trabalho localizada em "Isaías 2,17", mas que na Bíblia está em Isaías 1,17/18):

"aprendei a fazer o bem: procurai o que é justo, socorrei ao oprimido, fazei justiça ao órfão, defendei a viúva.

E vinde, arguí-me, diz o Senhor: se os vossos pecados forem como a escarlata, eles se tornarão brancos como a neve, e se forem roxos como o carmezim ficarão alvos como a branca lã.",

que considera "claramente dirigida aos advogados" (as palavras bíblicas, as copiamos da tradução do Padre Antonio Pereira de Figueiredo, em edição Barza de 1966 - que não deve ter sido a usada pelo Autor do estudo referido).

Estas palavras, mostram quão antiga é a existência do advogado, e sua importância.

Em aula de encerramento do I Curso de Extensão de Direito do Trabalho e Processo do Trabalho (Faculdade de Direito da Universidade Federal do Paraná - 1976), publicada na reviśta LTr (São Paulo, vol. 40 - pp. 1.528/1.532), cuidamos da especialização das funções do Estado, e da especialização desses órgãos, em razão das "questões a julgar ou das pessoas envolvidas", daí surgindo os juízes e justiças especializadas.

Prosseguindo, afirmamos que

R. Fac. Direito Curitiba

a. 25

ก. 25

p. $125-137,1989$ 
"As mesmas razões de complexidade das questões e, mais, das regras a seguir na submissão dos casos ao julgador, levaram ao surgimento, antes mesmo da separação entre a função de julgar e as demais, de uma figura que, ao lado ou em substituição, do interessado, se encarregava de expor suas razões, defendê-las e procurar fazê-las vencedoras.

Esta figura é o advogado, fruto da necessidade de o interessado ter por si alguém que, entendendo as normas, as interpretasse; por si conhecendo o caminho e a forma, apresentasse seu caso, os fatos, a norma e a interpretação ao julgador. Especialmente, no entanto, o advogado é alguém que, sem estar sofrendo na pele ou no patrimônio os efeitos da ação ou da omissão de terceiro, pode ter a ponderação indispensável à análise dos fatos e da norma, e à aplicação desta àqueles.

$$
\text { * * * }
$$

Generalizou-se a atuação do advogado, a ponto de hoje só por exceção se admitir que a parte esteja em juízo sem ele, na Justiça comum (Cível e Criminal).

Exige-se o advogado nas ações criminais e nas cíveis. Admite-se que a parte ou qualquer do povo requeira "habeas corpus" (artigos 654 do Código de Processo Penal, 470 do Código de Processo Militar e 184 do Regimento Interno do Supremo Tribunal Federal). Admite-se a parte advogando em causa própria, quando, sendo devidamente habilitada para c exercício da advosacia, o requeira ao juiz; quando não haja advogado na sede do juízo ou, havendo, ele recuse a causa ou (fundamentadamente) não lhe mereça confiança (artigos 36 do Código de Processo Civil vigente, $\S 1$ o do artigo 106 do anterior e 75 da Lei no 4.215/63).

A primeira exceção (a do "habeas corpus") é justa: tolhida ou em risco a liberdade de ir e vir, não seria lógico fazer depender sua defesa da disponibilidade de um advogado. A terceira se justifica para situação irremovível. Mas a segunda, 
não, pois à parte, embora legalmente habilitada, faltará aquela ponderação indispensável a uma correta análise dos fatos e da norma.

Fora de tais exceções, exigem os Códigos de Processo Civil (artigos 36 do atual e 106 do anterior), de Processo Penal (artigos 32, 261 e 564, III, "c", do vigente) e de. Processo Penal Militar (artigo 71), a presença do advogado.

Portanto, a lei exige, e corretamente 0 exige, a presença do advogado.

É um monopólio, conforme afirmação de Ruy de Azevedo Sodré (A Presença Obrigatória do Advogado na Justiça do Trabalho, in LTr São Paulo, vol. XXVIII, pp. 141/145), mas que se justifica, na palavra de Herotides da Silva Lima (que foi desembargador no Tribunal de Justiça de São Paulo), por ele citada, porque

'a intervenção de pessoas incompetentes na instrução e marcha dos atos judiciais, traria logo a anarquia, porque nada entendendo ou entendendo mal a função de processar, perturbariam a boa marcha das ações, com atitudes e discussões ineptas ou infundadas e causando os danos que o charlatanismo sóe provocar',

por onde vemos que esse monopólio não é odioso porque não vem em benefício do advogado, e sim, no da Justiça.

De fato, o advogado, competente e honesto, é de grande ajuda ao juiz, porque lhe traz os fatos e suas provas, a norma e sua interpretação para adequá-las ao fato, e isto afirmo com a experiência de meus quinze anos de magistratura. Não significa isto, que o juiz se louve na palavra do advogado para apenas dizer 'amém', mas que a tome como apoio para suas próprias investigações e interpretações.

2. Mas - e é o mesmo estuđo já referido (apresentado no 
Simpósio de São Paulo) que nos traz auxílio - os advogados têm enfrentado períodos de hostilidade, como sob "a lei de D. Afonso (Livro das Leis e Posturas - Ed. da Universidade de Lisboa, 1941, p. 439) assim vazada:

‘... Tenho por bem e ponho por lei para sempre e mando que daqui adiante non aiam vogados nem procuradores .....",

ou quando, na Revolução Francesa foram "identificados com a opressão e os privilégios do 'Ancien Regime', porque se opunham às condenações em massa", ou quando Napoleão Bonaparte "aferrolhou a Ordem dos Advogados precisamente porque se opunham os causídicos a seus propósitos despóticos" ou, ainda, quando "um dos primeiros atos do governo soviético foi abolir completamente a advocacia".

No Brasil, o período de hostilidade se acentuou desde 1939. Na aula mencionada dissemos que

"No entanto, ao se cuidar da solução dos problemas emergentes das relações entre empregados e empregadores, fez o legislador um retrocesso de séculos, para permitir que o empregado fosse pessoalmente, e sozinho, ao encarregado de acertar as situações litigiosas. Voltou ao tempo em que a parte ia ao pretor pedir justiça, em que o homem ia ao rei, ou ao procurador do rei, contar suas quizilas com o vizinho e pedir solução.

Por assim permitir ao empregado, o mesmo permitiu, em respeito à eqüidade, ao empregador.

Isto constou no Decreto-lei no $1.237 / 39$, no Decreto no 6.596/40 e no artigo 791 da Consolidação das Leis do Trabalho. Diz este último dispositivo:

'Os empregados e os empregadores poderão reclamar pessoalmente perante a Justiça do Trabalho e acompanhar as suas reclamações até o final", completando o disposto em artigos anteriores que prevêm a possibilidade de reclamação apresentada oralmente.

Prosseguindo, afirmamos que

Por ocasião do Decreto-lei no $1.237 / 39$, do Decreto no 6.595/40 e da promulgação da Consolidação das Leis do Trabalho, como a função de decidir os litígios trabalhistas estava entregue a órgãos administrativos, do então do Ministério do Traba- 
lho, Indústria e Comércio, poder-se-ia aceitar aquela anomalia.",

embora o então vigente Regulamento da Ordem dos Advogados do Brasil dispusesse em seu artigo 22, que

"em qualquer juízo, contencioso ou administrativo, cível ou criminal, salvo quanto a habeas corpus, o exercício das funções de advogado, provisionado ou solicitador, somente será permitido aos inscritos no quadro da Ordem ..."

e outro artigo: considerasse funções do advogado a apresentação de petições iniciais (e a reclamação, ainda que oral, é uma petição inicial) de defesas (a contestação o é) e o acompanhamento dos processos.

Como então dissemos, era possível

"aceitar que referido Decreto-lei no 1.237/39 houvesse derrogado o dispositivo do Regulamento da Ordem, por ser posterior e se referir ao mesmo assunto.".

Todavia, como expusemos e indagamos na mesma aula “ ... em 1946, a Assembléia Constituinte, corrigindo velho erro, colocou a Justiça do Trabalho onde sempre deveria estar: no Poder Judiciário.

Integrada a Justiça do Trabalho no Poder Judiciário, e sendo o Código de Processo Civil subsidiário das normas de processo da meșma Justiça, cabia então apiicar-lhe a disposição de seu artigo 106, que exigia, como o artigo 36 do atual exige, a presença do advogado.

No entanto, até hoje continua a ser aceita a expulsão do advogado do foro trabalhista, continua a ser aplicado o artigo 791 da Consolidação das Leis do Trabalho.

Por que se quis afastar o advogado da Justiça do Trabalho?",

e continuamos a perguntar:

"Será que em matéria de trabalho a lei é tão clara, tão simples' que apesar de 0 índice intelectual do empregado e do empregador não ser normalmente è̀evado elès possam interpretá-la?

Será tão simples fazer justiça em matéria de trabalho, que o juiz posșa dispensar a ajuda do profissional?",

para respondermos a seguir: 
"Minha experiência diz que não. Em quinze anos de exercicio como Juiz do Trabalho e, depois disso, sete como advogado, e antes, como funcionário da Secretaria e como Secretário do então Conselho, hoje Tribunal, Regional do Trabalho, totalizando trinta e cinco anos de ligação com a Justiça do Trabalho, nada vi que permita dizer que seja mais fácil fazer justiça em matéria de trabalho do que em outra. A iei que regula as relações de trabalho é tão complexa quanto qualquer outra, se não for mais. Os fatos que suportam os direitos por ela disciplinados, são tanto ou mais difíceis de provar e analisar do que os dos demais direitos.

Tenho dito, e há poucos dias repeti, a meus alunos, que a advocacia no Direito do Trabalho exige conheça o profissional, não só o Direito do Trabalho e o Processual do Trabalho, mas todos os outros ramos do Direito, dadas as freqüentes remissões que a eles deve fazer. Por exemplo, o artigo 482 da Consolidação das Leis do Trabalho, fala em 'legítima defesa', mas no Direito Penal é que vamos saber o que ela é; o artigo 815 fala em testemunhas, mas no Direito Processual Civil e no Civil é que se diz quem pode e quem não pode testemunhar; os artigos 2 e 10 falam em empresa, mas o Direito Comercial é que a define.

Mais, ainda, por vezes precisará fazer incursões por outros campos fora do Direito. Todo um capítulo da Consolidação das Leis do Trabalho se baseia na medicina e/ou engenharia (Capítulo sobre segurança e higiêne do trabalho), outras vezes necessitará conhecer economia política (quando se trata de fixação de salários normativos), etc., etc. ...

Isto para não falar na boa dose de conhecimento psicológico e de habilidade em relações humanas, que muitas vezes faz o sucesso na defesa dos interesses do cliente.",

e voltar a indagar:

"Onde, então, a simplicidade que permita ao analfabeto ou apenas alfabetizado, patrão ou empregado, movimentar-se em juízo na defesa de seus 
direitos? ou mesmo ao inteligentíssimo e eficiente profissional de outro ramo que não o Direito?

Então, por que se permitiu e se permite referida exceção?

e a responder, intercalando perguntas:

"Porque,

'Entendia-se que a presença do advogado era nociva aos interesses do operário, não só porque eliminava da reclamação aquele cunho realista e humano consubstanciado na expressão então usada de "ação de presença", como tornava mais burocratizado o seu processamento.', segundo informa Ruy Sodré (artigo citado), ou seja, porque havia, e há, o preconceito contra o advogado, não apenas entre nós, mas também naqueles países dos quais o Estado Novo copiou a legislação.

E verdade, infelizmente o é - e que não pode ser mascarada, haver advogados que não têm sabido honrar seu juramento, o 'Ego promito me', e têm agido mais em seu próprio do que no interesse do cliente. E verdade, lamentável também, que muitos advogados têm menos condições de estar em juízo do que seus clientes; menos cultura, menos inteligência, menos conhecimento do Direito do que seus próprios clientes.

Mas isto não ocorre somente nas questões de Direito do Trabalho. No foro cível e no criminal, e principalmente neste, eles pululam, e nem por isso pensou o legislador em admitir a parte sem advogado na Justiça comum.

É o preconceito que impera e encontrou eco entre doutrinadores do Direito do Trabalho.

Diz-se que o bacharel tudo complica, é formalista, apega-se a nugas, retarda a marcha do processo. Mas se isto for verdade, o será também nos outros ramos do Poder Judiciário. Por que, só na 
Justiça do Trabalho se eliminará o advogado?

Por que a causa do trabalhador deve ser rápida, e não o deverá ser a do réu em processo criminal, que tem sua liberdade tolhida ou ameaçada? e não o deverá ser a da mulher e/ou filho que pede alimentos? e a do proprietário ou possuidor turbado ou ameaçado em sua posse? e a do credor, muitas vezes sujeito ele à falência porque o devedor não the paga?

Se fosse questão de rapidez, em nenhuma dessas e de outras causas deveria exigir a presença do advogado.

Seria para favorecer ao trabalhador?

Se esse foi o objetivo, a solução foi desastrosa: a parte sem advogado, para propor a ação, já principia a ser prejudicada na lavratura do termo de reclamação: porque o funcionário que o lavra irá julgar o que é e o que não é importante em tudo quanto o interessado lhe disse, para só consignar o que lhe parece que é, e, muitas vezes, seu julgamento é errado; (o mesmo ocorre com o empregador, tem sua defesa reduzida a termo na audiência, num prejulgamento, pelo juiz, do que é e do que não é relevante); depois, na audiência, frente ao juiz e ao advogado da outra parte, já será natural sua inibição; depois, na produção de provas, sua ignorância a respeito terminará de prejudicála; isto para não falar nas exceções a serem impugnadas dentro de vinte e quatro horas: apresentada a exceção de incompetência, o trabalhador não sabe 0 que isto significa (pode, até mesmo; pensar em ofensa ao juiz), mas tem vinte e quatro horas; prazo improrrogável, para impugná-la; terá que conseguir advogado que o faça - conseguirá? a que preço?

Diz-se que ao Vogal caberá ajudá-la. Mas isto é absurdo, é heresia: o vogal è juiz, e juiz há-deser imparcial, não pode patrocinar ningguém; Juiz que faz as vezes de advogado da parte deixa de ser Juiz. O mesmo se diga do Juiz Presidente da Junta.

a. 25

n. 25

p. $125-137,1989$ 
Termina, pois, essa errada solução encontrada pelo legislador, por đeitar por terra, em juízo, toda a proteção que no direito material procurou dar ao trabalhador, porque se em Juízo é ele mal sucedido, de nada adiantou o direito que a lei lhe assegurou e que o empregador the negou.".

Procuramos naquela aula, uma explicação para o preconceito contra o bacharel:

“ ... é, talvez, uma reação contra a situação passada.

Há anos atrás, ser bacharel era estar habilitado a ser preferido para tudo: política, legislatura, diplomacia, direção de empresas e repartições, e, até, para ser genro do fazendeiro rico.

Hoje, o bacharel vem sendo alijado de tudo: a diplomacia exige curso especial, a política e a legislatura não exigem curso algum, a administração e a economia estão entregues a técnicos, e ... os fazendeiros ricos já não têm filhas apaixonadas por poesia, música e romance ...

Só falta que o explúsem do Poder Júdiciário, que os juízes passem todos a ser leigos, e isto já começou a acontecer: a Justiça do Trabalho já tem juízes classistas que, na Junta de Conciliação e Julgamento são, na verdade, os que julgam, como exposto a pouco.".

3. tempo de reagir.

preciso obter a expressa revogação do artigo 791 da Consolidação das Leis do Trabalho, que dispõe:

"Os empregados e empregadores poderão reclamar, pessoalmente: perante a Justiça do Trabalho e acompanhar suas reclamações até o final.", que confere às partes o "jus postulandi", que dispensa a presença dos advogados.

Esse artigo está revogado desde que a Lei no 4.215/63 (Estatuto da Ordem dos Advogados do Brasil), em seu artigo 159 declarou revogadas as "disposições em contrário" ao que nela se contém. Está revogado o artigo 791 da Consolidação das Leis do Trabalho, porque contraria o disposto no artigo 67 combinado com 0 71 e o parágrafo 30 deste, de referido Estatuto, que estabelecem:

"Art. 67 - O exercício das funções de advogado, estagiário e provisionado somente é permi- 
tida aos inscritos nos quadros da Ordem dos Advogados do Brasil, e na forma desta lei (art. 56).

Parágrafo Único - A denominaçầo de advogado é privativa dos inscritos no quadro respectivo (arts. $4^{i}$, inciso I e 128).

Art. 71 - A advocacia compreende, além da representação em qualquer juízo ou tribunal, mesmo administrativo, o procuratório extrajudicial, assim como os trabalhos jurídicos de consultoria e assessoria e as funções de diretoria jurídica.

$\S 39$ - Compete privativamente aos advogados elaborar e subscrever petições iniciais, contestações, réplicas, memoriais, razões, minutas e contraminutas nos processos judiciais, bem como a defesa em qualquer foro ou instância.".

Mas assim não vêm entenđendo os Tribunais, que continuam a admitir 0 "jus postulandi" das partes. Por isto se faz necessário pieitear a expressa revogação do artigo 791.

Não é argumento aceitável, para justificar o "jus postulandi", a miséria do trabalhador, sua impossibilidade de pagar advogado, pois também no juízo cível e no criminal há autores e réus miseráveis, e nem por isto são dispensados de ter advogados.

Ademais, é obrigação do Estado dar assistência jurídica (incluindo advogado) a quem dela necessite. Acresce, ainda, que por força do disposto nos artigos 14 e seguintes da Lei nọ 5.584/70, ao Sindicato incumbe a obrigação de dar assiștência a qualquer membro da categoria (seu associado ou não) que precise litigar contra o empregador e não possa pagar advogado (ou se presuma não poder, por ganhar o dobro do salário mínimo ou menos do que isto).

Para cobrir esta obrigação, recebem os sindicatos parte de "contribuição sindical" anualmente descontada pelos empregadores dos salários de todos os empregados (sindicalizados ou não) e, se vencedor o reclamante, ainda recebem honorários advocatícios pagos pelo vencido.

4. Insistimos: o artigo 791 da Consolidação já está revogado desde 1963, porque incompatível com os artigos 67 e 71, e seu $\S 3$, , da Lei no 4.215/63.

Mas há autores (e juízes) que, admitindo essa revogação, afirmam ter sido restabelecido o artigo 791 pelo artigo 40 da Lei no $5.584 / 70$.

R. Fac. Direito Curitiba a. 25 n. 25 p. 125-137, 1989


"Data venia", não houve tal repristinação. Não houve, porque a repristinção há de ser expressamente declarada ( $\$ 3$ ? do artigo $2^{\circ}$ da Lei de Introdução ao Código Civil), e a Lei nọ 5.584/70 não a declarou. Diz o artigo 49 invocado:

"Nos dissídios ... em que os empregados e empregadores reclamarem pessoalmente, o processo poderá ser impulsionado de ofício pelo juiz.", sem qualquer referência ao artigo 791 ou concessão de "jus postulandi". O artigo 4\%, apenas, contém a suposição de que haja dissídios em que as partes possam atuar pessoalmente, suposição falsa, sem fundamento, desde que o artigo em que ela se baseou (o 791) estava revogado.

Nem se invoque a afirmação de que "na lei não há palavras inúteis", porque, na verdade, a totalidade do artigo é inútil: é obrigação de o juiz movimentar o processo, impedir sua paralização fora dos casos em que a lei a determine ou permita, e por isto está ele investido do poder de direção do processo e obrigado a darlhe celeridade e a agir "ex-officio":

"Os juízos e Tribunais do Trabalho terão ampla liberdade na direção do processo e velarão peło andamento rápido das causas, podendo determinar qualquer diligência necessária ao esclarecimento (artigo 765 da Consolidação).

Dizer-se que a Justiça age apenas quando provocada, para justificar que o procedimento fique paralisado à espera de atuação da parte, é desculpa para a negligência do juiz ou do funcionário do juízo. A provocação, para que a Justiça atue, é feita através da petição inicial (no processo penal, pela denúncia ou queixa). Após ela, a Justiça deve parar apenas após a decisão da causa e trânsito em julgado da decisão (se não houver execução a fazer).

5. Como conseqüência de todo o exposto, propomos que em projeto de lei (ou em substitutivo a outros projetos em tramitação, referentes ao artigo 791 da Consolidação, como, v.g., o Projeto de Lei no 5.252/84) se procure aprovar lei que disponha:

"Art. 10 - Ficam revogados o artigo 791 e seus parágrafos, da Consolidação das Leis do Trabalho aprovada pelo Decreto-lei no 5.452 de 19 de maio de 1943.

Art. $2^{\circ}$ - Aplicam-se no que couber, aos processos na Justiça do Trabalho as disposições da Lei no 4.215, de 27 de abril de 1963 (Estatuto da Ordem dos Advogados do Brasil) e das leis pro- 
cessuais civis, relativas às presença e atuação do advogado e à assistência judiciária.

Art. 3 ? - Esta lei entra em vigor na data de sua publicação, revogadas as disposições em contrário.".

Será mais uma homenagem à memória do ADVOGADO José Lamartine Corrêa de Oliveira Lyra. 